Portland State University

PDXScholar

Fall 2021

\title{
Fandom in the Digital Age: Examining Parasocial Relationships Between Fans and Music Artists on Instagram
}

Brittani Wert

Portland State University

Follow this and additional works at: https://pdxscholar.library.pdx.edu/honorstheses

Part of the Marketing Commons, and the Social Media Commons Let us know how access to this document benefits you.

\section{Recommended Citation}

Wert, Brittani, "Fandom in the Digital Age: Examining Parasocial Relationships Between Fans and Music Artists on Instagram" (2021). University Honors Theses. Paper 1146.

https://doi.org/10.15760/honors.1177

This Thesis is brought to you for free and open access. It has been accepted for inclusion in University Honors Theses by an authorized administrator of PDXScholar. Please contact us if we can make this document more accessible: pdxscholar@pdx.edu. 
Fandom in the Digital Age: Examining Parasocial Relationships Between Fans and Music Artists on Instagram

by

Brittani Wert

An undergraduate honors thesis submitted in partial fulfillment of the requirements for the degree of

Bachelor of Arts

in

University Honors

and

Communication Studies

Thesis Adviser

Dr. Erin Spottswood

Portland State University

2021 


\begin{abstract}
With the rise of social media as a cultural staple in entertainment industries such as music, Instagram changes the landscape of the artist-fan connection and muddles the boundaries of parasocial relationships in a digital space. While a wealth of research exists on how fans perceive mediated relationships, the perspective of the artist and how they navigate this connectivity is missing from the discourse. This study builds on the current literature surrounding mediated artist-fan interactions and examines how music artists use Instagram to build strong, loyal relationships with fans through the lens of parasocial relationships. Through interviews with upand-coming artists and music industry professionals, this study concluded that in using Instagram to build valuable fan connections, artists view online interactions as mutually beneficial for fans and themselves, and build a community around their music through self-disclosure and providing more valuable content to followers. While these parasocial relationships crafted through Instagram may not grant fans full access to their favorite artists, the opportunity for artists to engage with their fans can still blur the boundaries of a true parasocial relationship.
\end{abstract}

Keywords: parasocial relationships, music artists, Instagram, social media, loyalty, music industry

\title{
Introduction
}

In the current age of technology, social media users are more connected than ever in the dynamic online world. Platforms like Instagram bridge the gap between music artists and fans and emphasize the ever-growing importance of building and nurturing a fan base online. While every artist and fan base may have varying experiences with social media, it is clear that social 
media continues to change the landscape of the artist-fan connection and muddle the boundaries of these parasocial relationships. As Willy Perez-Feria, a music producer and songwriter, claims, artists can't be successful "in the 21 st century without having some commitment to connecting to their fans. [They] cannot be an artist and ignore social media, that's how powerful social media has become in the music world" (Garcia, 2016, p. 68). While a wealth of research exists on how fans perceive mediated relationships, the perspective of the artist and how they navigate this connectivity is missing from the discourse. This study aims to build on the current literature surrounding mediated artist-fan interactions and examine how music artists use Instagram to connect and build loyal relationships with their fanbase.

\section{Literature Review}

Initially coined by researchers Horton and Wohl in 1956, a parasocial relationship (PSR) is defined as a one-way mediated relationship where the audience experiences the illusion of a personal relationship with a media personality (Reinikainen et al., 2020). Though examined initially through the lens of television, this concept has since grown to include relationships formed in online spaces. The concept of parasocial relationships has become prominent with the rise of celebrity and influencer culture on social media. These platforms allow followers to connect with their favorite users more personally as celebrities share their daily lives and allow celebrities to connect more regularly with their fans. This ultimately bridges the gap between the two groups. This concept can also be seen in the interactions between music artists and fans on social media as the music industry moves through the digital space and artists become more in tune with online fan engagement. The internet and social media have created an abundance of 
new possibilities for artists to promote themselves and their music, expand their fanbase, and share music without the restrictions of physical formats.

While there is a wealth of literature examining the fan's perspective of PSRs with artists, there is a significant gap in research from the artist's perspective of parasocial relationships with fans (Baym, 2013). The small number of current findings show that social media has evolved the communication between artists and their audience, blurring the line between fan and friend in some instances (Baym, 2013). Artists have to manage an evolving set of boundaries and accessibility while engaging with their dynamic digital fanbase. Social media interactions have challenged the power separation of fan and artist, placing fans in the role of "relational partners" (Baym, 2013, p. 313). Fans can provide motivation for the artist and help build a community around the music; these interactions can be just as beneficial for artists as they are for fans.

Despite this shift of power, there is still some argument about the true reciprocity that can be achieved in these artist-fan relationships. Though some research argues that social media increases interactivity, two-way communication is still generally infrequent due to the volume of fans online, so artists and fan relationships should still fall into the parasocial category rather than a more intimate connection (Ledbetter \& Redd, 2016). To acknowledge the complex dynamic of mediated communication, Garcia (2016) created the term "semi-reciprocal interaction" to better describe the interactivity that social media affords between fans and artists. Because traditional media allows for no reciprocity as fans cannot respond directly to the artist, and limits of access deny a genuinely reciprocal relationship, social media affords some reciprocity because of the ability to send and receive messages.

\section{Instagram}


RUNNING HEAD: Fandom in the Digital Age

Instagram is a social media platform focused on photo-sharing that launched in October 2010 (Blystone, 2020). With over one billion users worldwide and 112 million in the United States alone as of 2020, Instagram is a massive platform to connect with users and celebrities of all demographics (Tankovska, 2021). As of July 2021, 25.7\% of users in the United States were aged 18 to 24, and $31.4 \%$ of users were aged 25 to 34 (Distribution of Instagram users...by age group, 2021). $57.9 \%$ of these users identified as female, and $42.1 \%$ identified as male (Distribution of Instagram users... by gender, 2021).

Instagram contains various features that allow for a range of content to be posted and many ways to interact with other users. The most prominent feature of Instagram is the static, infeed posts that live on a user's profile and make up the general news feed of posts shown to a user. A second content sharing feature is Instagram Stories, which take a more ephemeral approach where users can post content that is only available for other users to see for 24 hours and does not impact their in-feed posts. Stories can be edited with text, stickers, GIFs, or filters, and users can add things such as music, a location, the temperature, or mention another user by their username. Users can interact with content and others by liking posts, commenting on posts, replying to Stories, and using direct messaging (DM) to talk to specific users. In a March 2020 study examining Instagram activity from users in the US, $42 \%$ of participants said they watched other people's Instagram Stories in the past month, and 39\% of participants said they scrolled through their feeds for posts from friends or accounts they were following (Most popular Instagram activities, 2021).

Social Media in the Music Industry 
As social media becomes an integral part of modern society and culture, it also permeates the music industry and can become a crucial part of an artist's marketing strategy. One study of artists in the Netherlands explored how artists at different levels in their careers use social media and other tools to market their music and generate revenue. The study found that independent artists, those without a traditional record label behind them, are more likely to use and benefit from social media and the live music industry to build and manage fan relationships (Leenders et al., 2015). Utilizing social media means that a smaller artist can start to build a supporter base in a way that is much less expensive and more accessible than traditional marketing methods, which is desirable as they don't yet have the money and access to more extensive networks that would come with a record label. And for artists that do have the support of a record label behind them, the use of social media is even more significant as they will have funding and connections to grow a fan base even quicker (Leenders et al., 2015). Social media is beneficial from a marketing and sales perspective, so fostering PSRs to develop that fan base in the digital space is profitable and worthwhile for an artist's success.

Garcia (2016) also highlights that social media can provide the opportunity for artists to grow and reach new audiences like never before, increase brand awareness by digital word-ofmouth, gather data about followers, and promote new music quickly and effectively to fans. Fan participation and interaction allow musicians to bring fans into their world of music, thereby increasing fan loyalty and eventually revenue (Garcia, 2016).

\section{Self-Disclosure}

Self-disclosure, or the "voluntary sharing of personally relevant information such as feelings, thoughts, values, and beliefs," also becomes a prominent element of content to focus on 
RUNNING HEAD: Fandom in the Digital Age

in building parasocial relationships (Kim \& Song, 2016, p. 571). Stemming from the concept of Social Penetration Theory, humans are shaped by layers of information, from peripheral layers involving demographic information to central layers like personal values. And when one reveals these layers to other people, that self-disclosure aids in building a relationship (Kim \& Song, 2016). Research from 2013 shows that $53 \%$ of people say that "the more an artist shares online about themselves, the closer they feel to them," and more than $75 \%$ of Millennials connect more with artists who are more open (Garcia, 2016, p. 68). One study of celebrities on Twitter argues that one's professional and personal self-disclosure creates the feeling of a more substantial social presence, and thus a stronger parasocial interaction from the fan's perspective (Kim \& Song, 2016). This implies that celebrities self-disclosing online, both personally or professionally, can see more favorable perceptions from fans by making them feel like they are a part of the celebrity's life. This also implies that celebrities can capitalize on the opportunity to utilize social media as a "cost-effective marketing tool" outside of traditional media to gain attention and support (Kim \& Song, 2016, p. 575).

In their research with devoted Lady Gaga fans, known as "Little Monsters," Click et al. (2013) also finds support for a celebrity's authenticity, self-disclosure of personal experiences, and perceived reciprocity on fan loyalty and engagement. Their study found that Lady Gaga's prominent presence on social media, and her drive to speak up about empowerment, identity, and embracing differences, has built a community maintained by an "innovative reciprocal bond" that goes counter to a traditional fan-artist relationship (Click et al., 2013, p. 376). By sharing details of her life without the barrier of an external person running her social media, fans experience a sense of authenticity and intimacy with Lady Gaga. Though mediated amongst millions of followers, Lady Gaga's tweets provide fans with a feeling of talking directly with the 
artist. The case study concludes that social media can give artists an "aura of realness" and create intimacy by showing a more similar identity and encouraging more authentic interaction with fan-directed communication, thus altering the fan-artist relationship in the online space (Click et al., 2013, p. 366).

\section{Exclusive Content}

Regarding the specific content shared on social media, research has shown that exclusive or unreleased content from an artist is more impactful from the fan's perspective in boosting engagement and later purchase consideration (Salo et al., 2013). This further aligns with the idea that elements such as Instagram Stories allow for a more personal and behind-the-scenes look into an artist's daily life. These studies, however, do not address the celebrity's perception of putting more personal experiences online for the world or the delicate balance between sharing their personal life and marketing their music to further their career.

\section{Uses \& Gratifications}

Alongside specific research surrounding the interactions between fans, celebrities, and music artists on social media, an essential piece of this conversation includes the intersection between parasocial relationships and the concept of uses and gratifications. The uses and gratifications approach stems from the theory that media consumers engage with particular media and technology to fulfill specific needs (Pittman \& Reich, 2016).

Through the lens of uses and gratifications and platform affordances, Pittman and Reich (2016) examined how social media use impacts feelings of loneliness, happiness, and satisfaction in young adults. They compared image-based platforms such as Instagram and Snapchat, text- 
based platforms like Twitter and Yik Yak, and mixed platforms such as Facebook. The authors explain that people will attribute more credibility to visuals, thus increasing perceived authenticity and reducing loneliness. The conclusions show that image-based platforms like Instagram decrease loneliness, increase happiness, and increase satisfaction with life (Pittman \& Reich, 2016).

Additional findings show that when tied to music consumption, consumers use social media because of its reinforcement of social identity, the participation and two-way interaction affordances of social media, and the access to content it can provide; all of which are motivations that can also mediate the formation of parasocial relationships (Salo et al., 2013). Despite this research, there is an apparent lack of understanding about the uses and gratifications of the artists using social media to interact with fans. It's critical to understand why these artists are motivated to use social media, what they perceive to gain from it, and how that plays into the formation and strength of parasocial relationships with fans.

\section{Methods}

The methodology used for this research was comprised of qualitative data collected through semi-structured interviews that explored how music artists use Instagram to create parasocial relationships with fans and post-transcription thematic analysis.

RQ1: Using the idea of parasocial relationships, how can music artists use Instagram to build strong, loyal relationships with fans?

\section{Participants}

7 interviews were conducted throughout July and August $2021.57 \%$ of the participants identified as men, and $43 \%$ identified as women, all within the 20 to 35 year old age range. 
RUNNING HEAD: Fandom in the Digital Age

Participants included 4 up and coming musicians, 2 digital marketing professionals in the music industry, and 1 public relations professional. All participants either had experience using Instagram as an artist or worked very closely with artists using Instagram.

Call for participation in the study was advertised on a Facebook networking group targeted towards women and nonbinary people involved in the music industry, LinkedIn postings to connections and the general public, and Instagram Story posts for followers. Additional recruiting was conducted through snowball sampling and direct outreach. The recruitment posts gave an overview of the research and targeted perspectives, such as artists, digital marketers, and artist managers. The posts included the estimated time commitment for a virtual interview, a disclaimer that the interviews would be recorded, and that there would be no compensation for participation. Readers were directed to email the researcher for more information and to volunteer. Interested participants were emailed the consent sheet with more information about the study before an interview time was scheduled.

Interviews were conducted with every person that exhibited interest and established a meeting, as long as they had access to a computer or smartphone with a microphone and the Zoom application. No incentives were offered for participation. All research materials and processes were reviewed and approved by the Portland State University Institutional Review Board.

\section{Measures}

Two different interview schedules were created, one for participants that identified as artists and one for those that indicated they had roles in the music business. While the questions served as a guide, these interviews were conducted in a semi-structured format to allow 
participants to respond in as much detail as they wanted, allow for any follow-up questions that could describe their experience even further, and create a more casual conversation between participant and researcher.

Each schedule was comprised of 12 questions. Artists were asked to describe their experience using Instagram, how they interacted with fans, the types of personal and marketingfocused content they post, their use of in-feed posts and Instagram Stories, their engagement rates on different kinds of content, how engagement translates into other interactions, and how they perceive the relationship between themselves and their fans.

Participants working in the industry were asked to describe how much Instagram content is left to the artist's discretion, how much personal and marketing focused content their artists tend to post, how their artists use in-feed posts versus Instagram Stories, what kind of engagement they see on different types of content, how their artists interact with fans on Instagram, how they perceive their artists' Instagram accounts translating into other markers of success and fan loyalty, and how they perceive the relationship between artist and fan has changed as a result of Instagram.

\section{Procedure}

Semi-structured interviews were conducted with participants individually through Zoom, each interview lasting 20 to 35 minutes. The discussions were guided by a set of 12 questions, with the content depending on whether the participant was an artist or involved with an aspect of music business such as management, marketing, or PR. Interviews were recorded to the Zoom cloud storage, and an audio-only file was saved to a secure Google Drive to be transcribed. The 
RUNNING HEAD: Fandom in the Digital Age

interviews were transcribed, and a thematic analysis was conducted to identify recurring themes and patterns amongst the data.

\section{Results}

In the interviews with participants, it became clear that under the premise of parasocial relationships, the process of crafting loyal connections with fans through Instagram is incredibly multifaceted. Where media is posted within the app, what kinds of content is made available to fans, how artists interact directly with fans, and how artists perceive the artist-fan relationship all combine to craft a complex and multidimensional relationship mediated through the online space of Instagram. It is important to note that in discussions with industry professionals and artists themselves, artists have nearly complete control over what they want to post on their accounts, regardless of their levels of success or followers.

\section{Instagram In-Feed Posts versus Stories}

One facet of the Instagram experience as a music artist is the use of in-feed posts or the static posts that live continuously on an Instagram user's account. Participants shared that in-feed posts are reserved for the more official content and don't get used as often as Instagram Stories. Artists are more careful about what they post in-feed to maintain a more curated aesthetic, especially for more prominent artists and bands, as a professional from the digital marketing department at a major record label explained (Participant S). The owner of a public relations firm focusing on emerging artists described an artist's Instagram feed as a magazine with polished, long-form, and permanent content. The feed is a space for "the things that really mean a lot to me that I want to live on, the stories I want to tell, the legacy I want to leave" (Participant M). 
Instagram Stories are used very differently to engage fans and share information that is not always music-related, and Stories are being used daily by artists. A musician in the alternative/indie-rock genre described how she posts on her story every day to share snippets of her life, songs she has been listening to, or her friends' artwork (Participant E). As an administrative assistant in digital marketing at another major record label, Participant J, explained, a Story “only lasts 24 hours; there's not like an aesthetic or anything that lives for a longer period of time, so I think people are gravitating to posting more there way more frequently." An artist who ran his previous band's social media accounts, Participant B, described how he would use in-feed posts to announce an event ahead of time, then use Stories "so people could follow along with the event as we went through it" on that day. Stories serve as a way for artists to share more raw, behind-the-scenes content of their daily lives and interact with fans through features like resharing content, a Q\&A, and polls.

\section{Content}

Due to the affordances of Instagram and the variety of posting methods, a wide variety of content themes emerged from participant responses. Aside from the standard content to promote their music, such as sharing new music releases, music videos, or recent features, artists and music industry professionals all mentioned the presence of more behind-the-scenes content on artist Instagram accounts.

Images or videos showcasing the music process, like content inside the studio, making a music video, or live performances, were often mentioned. One alternative singer-songwriter, Participant K, explained how he posts this content "just to give people kind of a taste of what life is like as a musician because I've noticed a lot of people like seeing that behind-the-scenes 
stuff." Giving fans a more intimate look into the artistic process of songwriting was also an evident theme. This included content surrounding the meaning or story behind a song, the emotion behind a specific lyric, and why the artist wanted to use a certain kind of imagery to portray their emotions. With one recent song release, Participant K posted a short video clip talking about what the song meant to him and what he wanted listeners to take away from it. "That kind of personalization of videos is definitely a great tool to use... A lot of people were excited more about the song, and it was right before the song came out too, so they already had a really good idea of exactly what they were getting themselves into," he explains (Participant K).

As Participant $\mathrm{M}$ advises her clients, storytelling is central to the message of an artist and building connections online. "It's literally like 'here's how I feel' and 'here's what I was going through in this moment,' and maybe like 'here's a story that ties to the song,", she explained, "it doesn't matter how good your music is, you have to have a personality, you have to have a brand, you have to show that" (Participant M). Participant B described how he took an 80/20 approach to content on his band's social media pages. $80 \%$ of the content would be engaging for followers, like contests or topics that fans wanted to interact with, and $20 \%$ was the more streamlined promotional content to feature new songs or interviews.

While some artists will share about their daily lives, like Doja Cat, who is very active and candid on Instagram Live sessions, or Participant $\mathrm{K}$ sharing photos of his dog, artists do tend to remain relatively music-focused (Participant S; Participant K). As Participant R, an indie poprock artist, explained, "one of the biggest things as artists, or any content creator really, is to control your brand perception." By consistently posting content that depicts a day in the life of an average person, there may be a weaker association with your brand as an artist. New followers showing up on his Instagram account may not perceive him as a valuable artist to look further 
into. He gave the example of his favorite coffee shop playing his music in their store; if he posts a video of himself listening in the store, it's still organic content yet closely related to his persona and journey as an artist.

From the perspective of the industry, diversifying content will pay off for the unique brand of the artist. It's essential to alert fans of new music, "but you want something evergreen. You want something you can post on socials, or a content series, or whatever to just get people to like you," as Participant S explained. By showing the personality of an artist, that connection to fans is being created and strengthened. So when new music does release, there are already people to affiliate the music with that personality. As Participant J added, "if an artist is just going to post the album cover three times, obviously people are going to get bored of that. But if they're posting BTS [behind-the-scenes] shots that haven't been seen before, fans really love that kind of stuff, and it's still promotional material."

\section{Increased Value of Content}

With all of the avenues available to create content and interact with fans, a theme that became evident was the strategy and meaning behind posting. Many participants described the importance of providing valuable content through self-disclosure for fans and how that influenced the strength of the interactions. As Participant $\mathrm{M}$ explained, fans can connect to artists through their story and human experience, but not through a constant message of "listen to my music." She urges her artist clients to provide value to followers rather than always asking from their fans (Participant M).

Participant $\mathbf{J}$ noted a recent trend that artists have been posting more natural, casual content on Instagram, such as untouched selfies and relatable human emotions. "You see their 
personality, you see what they're like around their friends or backstage before a show, and like if you see them freaking out right before they go perform then like okay, they're the same way I would be if I was about to go on stage," she posited (Participant J). And with this relatability comes an increase in more intentional engagement. As Participant R explained, when he posts more genuine content, like "here's what the song is about and here's how when I was writing it, I was thinking about these things, and this is what it makes me reflect on now," he sees a lot of genuine responses in the comments and fans wanting to start a conversation. As Participant M reflected, when her artists intentionally post more valuable content and personal stories on Instagram, it elicits increased comments from fans relating to the artist. "I always see so much of some variation of like either, 'I feel this way too,' or 'I had no idea about this, and it's so good to know this about you," she said (Participant M). By posting content that portrays more emotion and relatability, artists can give their fans a opportunity to interact with more genuine versions of themselves outside of promotional content.

\section{Artist Interactions with Fans}

The affordances of Instagram allow for a variety of opportunities for artists to interact with fans. Nearly every participant mentioned the value of replying to comments on Instagram posts and liking those comments, which acts as a more public-facing interaction. This also included tactics like asking a question in a caption to elicit responses from fans to reply to in comments and stories and posting valuable content to spark conversations with fans in comments or direct messages (Participant S; Participant K). For more private interactions, artists utilize Instagram Story replies and direct messages (DMs) with fans wanting to start more extensive conversations, talk about the impact of their music on their lives or capture that more one-on-one 
experience (Participant B; Participant M; Participant R). Multiple participants also mentioned the ability to have more genuine interactions with fans as a smaller artist, compared to larger artists, and nurture that closer connection through more consistent interactions in comments and messages (Participant B; Participant E). By giving the space and the opportunity for fans to interact with the artist, the artist can use those public and private-facing interactions to continue building the relationship through ongoing conversations and repeated engagement.

\section{Artist Mindset}

Between the types of content and types of interaction utilized by artists on Instagram, it became evident that the driving force behind these behaviors was all centered around the artist's mindset and how they perceived the importance of building relationships with fans online. Instagram gives the opportunity for the connection between artists and fans to be deeper than ever, but the artists must decide to take advantage of that.

The most prominent idea that arose was viewing fan interaction as a positive thing, as an opportunity to connect and experiment with content, rather than simply a task or part of the job (Participant M). By wanting fans to be a part of the journey as an artist, the artist is fostering that more intimate connection and building a community around the music. As Participant B described, a big focus of his previous band was spreading the message of their music -spreading love and hope as far as sound could reach -- and being there for the fans that cared so much about them (Participant B). When the artist can see that the fans are engaged, they can return that and show interest in them. As Participant E explained, "Any relationship, if you take care of it, it's going to flourish, and you're going to have more committed people." By showing genuine interest in connecting with fans through Instagram content and online interactions, 
RUNNING HEAD: Fandom in the Digital Age

artists can truly connect with their fans rather than just posting for the sake of posting -- "It's really hard to manufacture personal touch" (Participant B).

However, it remains important to establish boundaries even in an online space. One artist, in particular, has worked to maintain clear boundaries in his relationships with fans. He strives for the interactions to be meaningful and appropriate but also scalable as his following grows. Though he tries to be someone who cares for his fans, he intentionally keeps his more personal content general and relatable to audiences rather than sharing specific details as he would in a relationship with a close friend. While he understands that fans may feel very close to him and want to share details of their lives, the relationship is significant, though not as strong for him (Participant R). Though the opportunity to nurture parasocial relationships exists within the affordances of Instagram, as with any user, artists must determine if and how they will do that to further support their success.

\section{Translating to Success}

Cultivating parasocial relationships between artists and fans on Instagram can ultimately lead to various measures of success for artists, both tangible and intangible. Data such as follower counts and presave numbers can be a good indicator of the artist-fan relationship and the building of fan loyalty. As artists post more content, fans will be more engaged, thus leading to more followers, which can all be tracked through Instagram analytics (Participant S). These analytics can also make it easier for artists and industry professionals to push fans directly from Instagram to links to presave songs on streaming platforms before their release date (Participant J). This provides artists and record labels critical insights into how the song will perform when 
available to the public and can provide a better understanding of how fans are engaging on an artist's Instagram.

However, for data relating to things like streams on Spotify and Apple Music, merchandise sales, or concert ticket sales, it can be challenging to determine where the actions originate (Participant R; Participant K). Fans could be driving traffic and sales through Instagram, advertisements, the artist's website, or several other places, making it difficult to conclude the most prominent source.

Finally, the most essential yet least measurable part of success comes in the form of building and maintaining fan loyalty. By allowing fans to come into the world of the artist, they can learn more about them as a person and form a deeper connection to the artist and the music, thus creating a stronger sense of understanding and loyalty to that person (Participant S). One particular example of creating lasting fan loyalty came from Participant B, who described how fans still listen to their music despite not having released anything in two years. They attribute the meaningful experiences with the band on social media with a more intimate connection to the band and music. By interacting with fans on Instagram, Participant B created and nurtured longlasting relationships, many of which have turned into friendships. While success from Instagram content and engagement may not be easily measured in the short-term, long-term results will emerge with loyal fans and continued support.

\section{Limitations of Instagram}

While Instagram does allow space for artists and fans to connect, it comes with some limitations that can inhibit the growth of these parasocial relationships and fan loyalty. Artists mentioned that Instagram is less community-based and does not encourage the same levels of 
RUNNING HEAD: Fandom in the Digital Age

interactivity between users compared to platforms like Facebook and Twitter (Participant K).

This is especially prominent in the case of private Facebook groups that circulate around conversation rather than Instagram that can be geared more towards engagement data and analytics (Participant $\mathbf{J}$ ). And even with the diminished boundaries that come with modern social media, nothing can compare to a live experience for fans or artists (Participant E).

\section{Discussion}

This study examined how music artists experience Instagram as a way to connect with fans and build parasocial relationships to foster a sense of loyalty and contribute to their success in the industry. Results show that music artists use Instagram to build these relationships through the strategic use of the Instagram feed and Stories and self-disclosure through specific kinds of content, like more realistic and behind-the-scenes images and videos, to provide more value to followers. Artists that intentionally use Instagram to cultivate parasocial relationships view Instagram as an opportunity to connect with fans and build community rather than simply part of the job. This ultimately strengthens the connection between parasocial relationships and the concept of uses and gratifications in that artists are using Instagram to satisfy a need for connection. However, while there was an emphasis on more personal and behind-the-scenes content, artists maintained boundaries and kept a large amount of their content music-oriented. There is some access to learn more about an artist as a person, but not full access as the content is still curated, which strengthens the argument around Garcia's (2016) concept of semireciprocal interactions and supports the idea that Instagram can blur the boundaries of a true parasocial relationship. 
RUNNING HEAD: Fandom in the Digital Age

Implications

This work has the potential to inform artists and music marketers of the best practices when it comes to using their Instagram accounts to engage with fans and build parasocial relationships and how fan interaction can then help their brand awareness and revenue. It is clear that in using Instagram to build strong, loyal relationships with fans, artists need to focus on building a community around their music and themselves through self-disclosure and view online interactions as mutually beneficial for fans and artists. The results further imply that social media works within a sort of ecosystem for artists based on the different affordances and expectations of each platform. Artists and marketers should understand what artists and followers want and how to tap into those motivations to build connection and loyalty on the right platforms with the right kinds of content for better engagement.

The current research was designed to build upon the small but growing discourse examining parasocial relationships between artists and fans online, and the results did align with conclusions established by previous research. Future research should explore artists with larger fan bases across various genres and demographics. Studies could include a content analysis of artist Instagram accounts to create a more well-rounded discussion of what artists post and how artist-fan engagement is present from a public-facing perspective.

\section{Limitations of Research}

This area of study presented a range of limitations. First, there is a limited amount of previous research regarding parasocial relationships from the perspective of the artist. There is a growing discourse on parasocial relationships with celebrities and influencers online, but less looking at the players in the music industry in particular, and even a smaller sample of research 
from the view of the artist. Because of this, the literature review is comprised of many different contexts that may not be generalizable to the music industry population. However, the gap in the research allowed this study to take a broad approach and gain a general understanding of how artists use Instagram and perceive interactions and relationships with fans.

Second, there were limits of budget and access in gathering participants to interview, resulting in a small sample size and limited scope. Participants identified as artists were more emerging musicians than more established artists who may have records labels or more assistance in running their social media accounts. However, this meant that the artists interviewed were able to provide a very in-depth perspective with their experience and growth on Instagram, and the music industry professionals were able to speak to broader trends and strategies. While the results are not necessarily generalizable to all artist experiences, this research can provide a framework for emerging artist interactions on Instagram and avenues for additional research.

\section{Conclusion}

In conclusion, Instagram as a platform has the potential to foster strong relationships between artists and fans. However, it is reliant on how the artist perceives the importance of cultivating parasocial relationships with fans and what the artist wants to get out of those relationships. There is strong potential for artists to use this research to understand what other artists are doing to build connectivity in their online worlds and how artists are tapping into those connections to strengthen the loyalty of their fanbase and contribute to their success. Artists and marketers should focus on building a community around the music and the artist's personality through self-disclosure and understand the opportunity for online interactions to be mutually 
RUNNING HEAD: Fandom in the Digital Age

beneficial for fans and artists. While these parasocial relationships may not grant fans full access to their favorite artists, Instagram can still blur the boundaries of a true parasocial relationship. 
RUNNING HEAD: Fandom in the Digital Age

Bibliography

Baym, N. K. (2013). Fans or friends?: Seeing social media audiences as musicians do. Matrizes,

7(1), 13. https://doi.org/10.11606/issn.1982-8160.v7i1p13-46

Blystone, D. (2020, June 6). The story of Instagram: The rise of the \# 1 photo-sharing application. Investopedia. Retrieved from https://www.investopedia.com/articles/investing/102615/story-instagram-rise-1photo0sharing-app.asp.

Click, M. A., Lee, H., \& Holladay, H. W. (2013). Making Monsters: Lady Gaga, Fan Identification, and Social Media. Popular Music and Society, 36(3), 360-379. https://doi.org/10.1080/03007766.2013.798546

Distribution of Instagram users in the United States as of July 2021, by age group. (2021, October 15). Statista. Retrieved from https://www.statista.com/statistics/398166/usinstagram-user-age-distribution/.

Distribution of Instagram users in the United States as of July 2021, by gender. (2021, October 15). Statista. Retrieved from https://www.statista.com/statistics/530498/instagram-usersin-the-us-by-gender/.

Garcia, K. P. (2016). The fan-artist relationship on social networking sites: A cyberstage pass for the music fan [M.A., St. Thomas University]. http://search.proquest.com/docview/1864650853/abstract/97DE1E07CF7545B6PQ/1

Kim, J., \& Song, H. (2016). Celebrity’s self-disclosure on Twitter and parasocial relationships: A mediating role of social presence. Computers in Human Behavior, 62, 570-577. https://doi.org/10.1016/j.chb.2016.03.083

Ledbetter, A. M., \& Redd, S. M. (2016). Celebrity Credibility on Social Media: A Conditional 
RUNNING HEAD: Fandom in the Digital Age

Process Analysis of Online Self-Disclosure Attitude as a Moderator of Posting Frequency and Parasocial Interaction. Western Journal of Communication, 80(5), 601-618. https://doi.org/10.1080/10570314.2016.1187286

Leenders, M. A. A. M., Farrell, M. A., Zwaan, K., \& Bogt, T. F. M. ter. (2015). How are young music artists configuring their media and sales platforms in the digital age? Journal of Marketing Management, 31(17-18), 1799-1817. https://doi.org/10.1080/0267257X.2015.1034158

Most popular Instagram activities in the United States as of March 2020. (2021, January 27). Statista. Retrieved from https://www.statista.com/statistics/1155196/share-of-instagram$\underline{\text { user-activities/ }}$

Number of Instagram users in the United States from 2019 to 2023. (2021, August 31). Statista. Retrieved from https://www.statista.com/statistics/293771/number-of-us-instagram-users/.

Pittman, M., \& Reich, B. (2016). Social media and loneliness: Why an Instagram picture may be worth more than a thousand Twitter words. Computers in Human Behavior, 62, 155-167. https://doi.org/10.1016/j.chb.2016.03.084

Reinikainen, H., Munnukka, J., Maity, D., \& Luoma-aho, V. (2020). 'You really are a great big sister' - parasocial relationships, credibility, and the moderating role of audience comments in influencer marketing. Journal of Marketing Management, 36(3-4), 279-298. https://doi.org/10.1080/0267257X.2019.1708781

Salo, J., Lankinen, M., \& Mäntymäki, M. (2013). The Use of Social Media for Artist Marketing: Music Industry Perspectives and Consumer Motivations. JMM: The International Journal on Media Management, 15(1), 23-41. https://doi.org/10.1080/14241277.2012.755682

Tankovska, H. (2021, May 12). U.S.: Average age of Instagram users. Statista. 
RUNNING HEAD: Fandom in the Digital Age

https://www.statista.com/statistics/398166/us-instagram-user-age-distribution/ 